\title{
The influence of Bitcoin on Portfolio Diversification and Design
}

\begin{abstract}
We employ a VARMA DCC-GARCH model to search for portfolio diversification with Bitcoin in global industry portfolios and bond index. We find lower dynamic conditional correlations between Bitcoin and industry portfolios \& bond index, allowing an investment in Bitcoin to hedge the risk against industry portfolios and bonds. The most effective hedge in a Bitcoin/industry (bond) portfolio is to short Utilities sector. Results are robust to the use of US industry portfolios and a cryptocurrency index instead of global industry portfolios and Bitcoin, respectively. Our results can help investors make informed decisions with regard to risk management and portfolio analysis.

Keywords: Bitcoin, DCC, Optimal Portfolio, Hedge Ratio, Diversification.

JEL Classification: G11, G12, G14, G15, G23.
\end{abstract}

\section{Introduction}

Bitcoin has received significant attention from investors, speculators, researchers and regulators. Much literature has focused on key questions, such as whether Bitcoin is a currency or speculative asset (Corbet et al. [2019]), its volatility dynamics (Katsiampa et al. [2019]), market inefficiency (Corbet et al. [2019], Sensoy [2019]), interactions with other assets (Corbet et al. [2018]), and the development of derivative products (Akyildirim et al. [2019]). In search of portfolio diversification, studies investigate at how Bitcoin is diversified with traditional financial assets and alternative investments (Selmi et al. [2018]), global and emerging equity markets (Kajtazi and Moro [2019]) and commodities (Dyhrberg [2016]). However, none has attempted how Bitcoin is diversified with industry portfolios and the bond markets. Our study attempts to fill the void in the literature.

We contribute in two ways. First, we provide the empirical evidence of lower dynamic conditional correlations (DCCs) between Bitcoin and industry portfolios \& bond index. Second, we find that the most effective hedge in a Bitcoin/industry (bond) portfolio is to short Utilities sector. The paper develops as follows: Section 2 describes the data empirical design, while Section 3 discusses the results of the volatility analyses, the estimate of optimal portfolio design and the associated hedging ratios. Sections 4 concludes.

\section{Data and Methodology}

Our sample period covers from 19 August 2011 to 30 November 2018 and includes daily data of Bitcoin, 11 industry sectors, and the global market sourced from DataStream. Additionally, we use the PIMCO Investment-Grade Corporate Bonds Index to include fixed income - Bitcoin portfolio analysis 
(Fang et al. [2019]). We choose the Bitcoin price from Bitsamp Exchange, because it is one of most popular, liquid and considered a safe exchange by market participants (Urquhart and Zhang [2019]). We choose the sample beginning in 2011, because in earlier periods the liquidity was low and Bitcoin price level and volatility were small (Kajtazi and Moro [2019]).

\section{Insert Table 1 about here}

Both mean return and volatility of Bitcoin are much higher than those of industry portfolios and PIMCO bond index. The Jarque-Bera test, Ljung-Box statistic, and Augmented Dickey-Fuller test provide evidence of non-normality, autocorrelation, and stationarity in returns, respectively. We employ various specifications of GARCH models to construct the optimum portfolios of Bitcoin, industry portfolios and bond index and chosen VARMA(1,1) DCC-GARCH model as a benchmark model based on information criteria, represented as:

$$
\begin{gathered}
r_{t}=c+\varphi r_{t-1}+\omega \varepsilon_{t-1}+\varepsilon_{t} \\
\varepsilon_{t}=H_{t}^{1 / 2} \eta_{t}
\end{gathered}
$$

where $c$ is the vector of constant terms. $r_{t}$ is a $n \times 1$ vector of returns on industry portfolios, bond index or Bitcoin. $\varphi$ and $\omega$ refer to a $n \times 1$ vector of coefficients for $\mathrm{AR}(1)$ and $\mathrm{MA}(1)$, respectively. $\epsilon_{t}$ is the vector of the error terms. $\eta_{t}$ is the sequence of independently and identically distributed random errors, and $H_{t}$ is the conditional variance-covariance matrix.

In a second-stage analysis, the optimal portfolio design allows investors invest in Bitcoin to hedge against industry portfolios and bond index. Following Kroner and Ng [1998], we determine the optimal weight of Bitcoin in a one-dollar portfolio of industry (or bond index) $i /$ Bitcoin at time $t$, denoted by $w_{t}^{(i / B i t c o i n)}$ :

$$
w_{t}^{i / \text { Bitcoin }}=\frac{h_{t}^{i}-h_{t}^{i / \text { Bitcoin }}}{h_{t}^{i}-2 h_{t}^{i / \text { Bitcoin }}+h_{t}^{\text {Bitcoin }}}
$$

where $h_{t}^{i}, h_{t}^{\text {Bitcoin }}$ and $h_{t}^{(i / \text { Bitcoin })}$ are the conditional volatility of the industry portfolio or bond index, Bitcoin and covariance, respectively at time $t$. However, under the assumption of no short-selling, the portfolio optimisation process imposes the following constraints:

$$
w_{t}^{i / \text { Bitcoin }}=\left\{\begin{array}{c}
0 \text { if } w_{t}^{i / \text { Bitcoin }}<0 \\
w_{t}^{i / \text { Bitcoin }} i f 0 \leq w_{t}^{i / \text { Bitcoin }} \leq 1 \\
1 \text { if } w_{t}^{i / \text { Bitcoin }}>1
\end{array}\right.
$$

To minimise the risk of the hedged portfolio, a long position of one-dollar in Bitcoin must be hedged by a short position of $\beta_{t}^{(i / \text { Bitcoin })}$ dollars in the industry sector, where $\beta_{t}^{(i / \text { Bitcoin })}$ is the optimal hedge ratio calculated as: 


$$
\beta_{t}^{i / \text { Bitcoin }}=\frac{h_{t}^{i / B i t c o i n}}{h_{t}^{i}}
$$

\section{Results}

\subsection{Volatility in Bitcoin, Industry Portfolios and Bond Index}

The one-period lagged Bitcoin returns, as measured by the $\mathrm{AR}(1)$ coefficient are presented in Table 2 , present evidence of a significantly influence on current Bitcoin returns. This largely presents evidence of short-term predictability in Bitcoin price changes. In Table 3, through analysis of the associated GARCH coefficients, we observe the presence of strong volatility persistence of returns. Hence, investors may consider active investment strategies based on such volatility persistence strength. The results of the Tse [2000] test rejects constant correlations, while our benchmark model passes diagnostic tests as both the Hosking [1980], and the Li and McLeod [1981] tests present no evidence of serial correlation and misspecification in the selected methodology, respectively.

\section{Insert Figures 1 and 2 about here}

\section{Insert Table 2 and 3 about here}

The dynamic correlations between Bitcoin and industry portfolios \& bond index appear to be quite low, as presented in Figure 2, varying from 0.0010 (Telecom) to 0.0395 (Basic Materials). DCCs vary across industries and markets states. As suggested by Cooper et al. [2004], we define the state of the market as Up (Down) when a one-year return is non-negative (negative). DCCs in the down market ( $\mathrm{n}=597$ days) are higher than those in the up market $(\mathrm{n}=1,304$ days). This result supports the literature that finds lower DCCs in economic downturns (Akhtaruzzaman et al. [2014], Akhtaruzzaman and Shamsuddin [2016]). Lower DCCs and variation in DCCs across industries and bond index provides an opportunity to diversify portfolios.

\subsection{Optimal portfolio design and hedging ratios}

Results presented in Table 4 and both Figures 3 and 4, demonstrate that in order to minimise the risk without lowering the expected return, investors should seek reduced exposure to Bitcoin. The estimated optimal weights are found to vary between 0.0043 (bond index) and 0.0602 (oil \& gas). The values of optimal hedge ratios are low, indicating that the potential for the opening of a highly effective hedge in the considered industry sectors and PIMCO bond index. For example, if we consider the hedging effectiveness for a Bitcoin and basic materials portfolio, a hedge ratio of 0.2552 implies that one-dollar long in Bitcoin should be shorted by 25.52 cents in basic materials.

\section{Insert Table 4 about here}




\section{Insert Figures 3 and 4 about here}

The optimal hedge ratios vary significantly across sectors and the bond index. Among all of the examined pairs, we find that the most effective strategy to hedge the Bitcoin risk exposure is to short the utilities sector which possesses the lowest optimal hedge ratio. In an examination of methodological robustness, we utilise United States industry portfolios and a cryptocurrency index to examine robustness and identify similar results ${ }^{1}$. These results suggest that Bitcoin can be a part of a diversified portfolio which increases the risk-adjusted performance.

Moreover, to check the robustness of the portfolio performance, we have presented the simulated portfolio returns and volatilities generated from optimal weights against individual industries and bond index in Figure 5. We find that all industry portfolios with Bitcoin have higher return and lower volatility than those of individual industries. However, the bond index portfolio with Bitcoin has higher return, but higher volatility than that of bond index only.

\section{Insert Figure 5 about here}

\section{Conclusions}

We analyse the performance of portfolio diversification through the addition of Bitcoin to global industry portfolios and PIMCO investment grade bond index. Results demonstrate lower dynamic correlations and substantial variation in relationships across industries and the bond index. Further, dynamic correlations are found to be substantially reduced during times of downturn. Results demonstrate that investment in Bitcoin provides an efficient hedging mechanism for a broad number of industrial sectors and bonds, with results found to be robust through the use of a cryptocurrency index and US industry portfolios. Our results help to inform investor decision-making when adding cryptocurrencies as part of the risk management and portfolio analysis process. Given the rise of cryptocurrencies as a currency or speculative investment, future research is warranted on whether it can be used to support diversification practices with financial assets across frontier, emerging and advanced economies in the context of future cryptocurrency regulation.

\section{References}

Akhtaruzzaman, M. and A. Shamsuddin (2016). International contagion through financial versus non-financial firms. Economic Modelling 59, 143-163.

Akhtaruzzaman, M., A. Shamsuddin, and S. Easton (2014). Dynamic correlation analysis of spill-over effects of interest rate risk and return on Australian and US financial firms. Journal of International Financial Markets, Institutions and Money 31, 378-396.

\footnotetext{
${ }^{1}$ For brevity, these results have been excluded but are available from the authors upon request.
} 
Akyildirim, E., S. Corbet, P. Katsiampa, N. Kellard, and A. Sensoy (2019). The development of bitcoin futures: Exploring the interactions between cryptocurrency derivatives. Finance Research Letters Available online at: https://doi.org/10.1016/j.frl.2019.0\%.00\%.

Cooper, M. J., R. C. Gutierrez, and A. Hameed (2004). Market states and momentum. Journal of Finance 59, $1345-1365$.

Corbet, S., V. Eraslan, B. M. Lucey, and A. Sensoy (2019). The effectiveness of technical trading rules in cryptocurrency markets. Finance Research Letters 31, 32-37.

Corbet, S., C. J. Larkin, B. M. Lucey, A. Meegan, and L. Yarovaya (2019). The volatility generating effects of macroeconomic news on cryptocurrency returns. Available at SSRN: http://dx.doi.org/10.2139/ssrn.3141986.

Corbet, S., A. Meegan, C. Larkin, B. Lucey, and L. Yarovaya (2018). Exploring the dynamic relationships between cryptocurrencies and other financial assets. Economics Letters 165, 28-34.

Dyhrberg, A. H. (2016). Hedging capabilities of Bitcoin. Is it the virtual gold? Finance Research Letters 16, 139-144.

Fang, L., E. Bouri, R. Gupta, and D. Roubaud (2019). Does global economic uncertainty matter for the volatility and hedging effectiveness of Bitcoin? International Review of Financial Analysis 61, 29-36.

Hosking, J. R. (1980). The multivariate portmanteau statistic. Journal of the American Statistical Association 75, 602-608.

Kajtazi, A. and A. Moro (2019). The role of Bitcoin in well diversified portfolios: A comparative global study. International Review of Financial Analysis 61, 143-157.

Katsiampa, P., S. Corbet, and B. Lucey (2019). Volatility spillover effects in leading cryptocurrencies: A BEKK-MGARCH analysis. Finance Research Letters, 29, 68-74.

Kroner, K. F. and V. K. Ng (1998). Modeling asymmetric comovements of asset returns. Review of Financial Studies 11, 817-844.

Li, W. and A. McLeod (1981). Distribution of the residual autocorrelations in multivariate ARMA time series models. Journal of the Royal Statistical Society 43, 231-239.

Selmi, R., W. Mensi, S. Hammoudeh, and J. Bouoiyour (2018). Is Bitcoin a hedge, a safe haven or a diversifier for oil price movements? a comparison with gold. Energy Economics 74, 787-801.

Sensoy, A. (2019). The inefficiency of Bitcoin revisited: A high-frequency analysis with alternative currencies. Finance Research Letters, 28, 68-73.

Tse, Y. K. (2000). A test for constant correlations in a multivariate GARCH model. Journal of Econometrics 98, $107-127$.

Urquhart, A. and H. Zhang (2019). Is Bitcoin a hedge or safe haven for currencies? An intraday analysis. International Review of Financial Analysis 63, 49-57. 

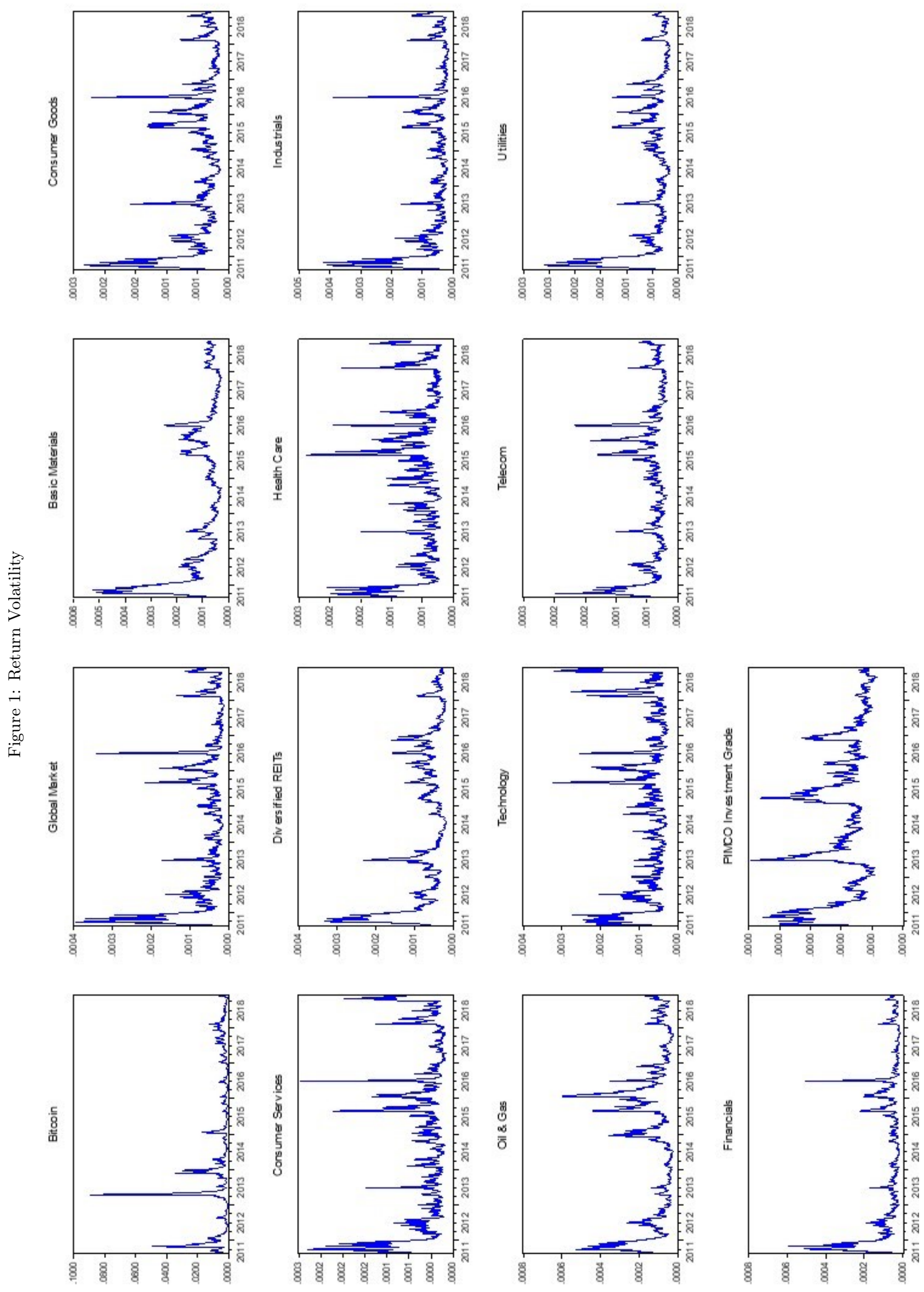

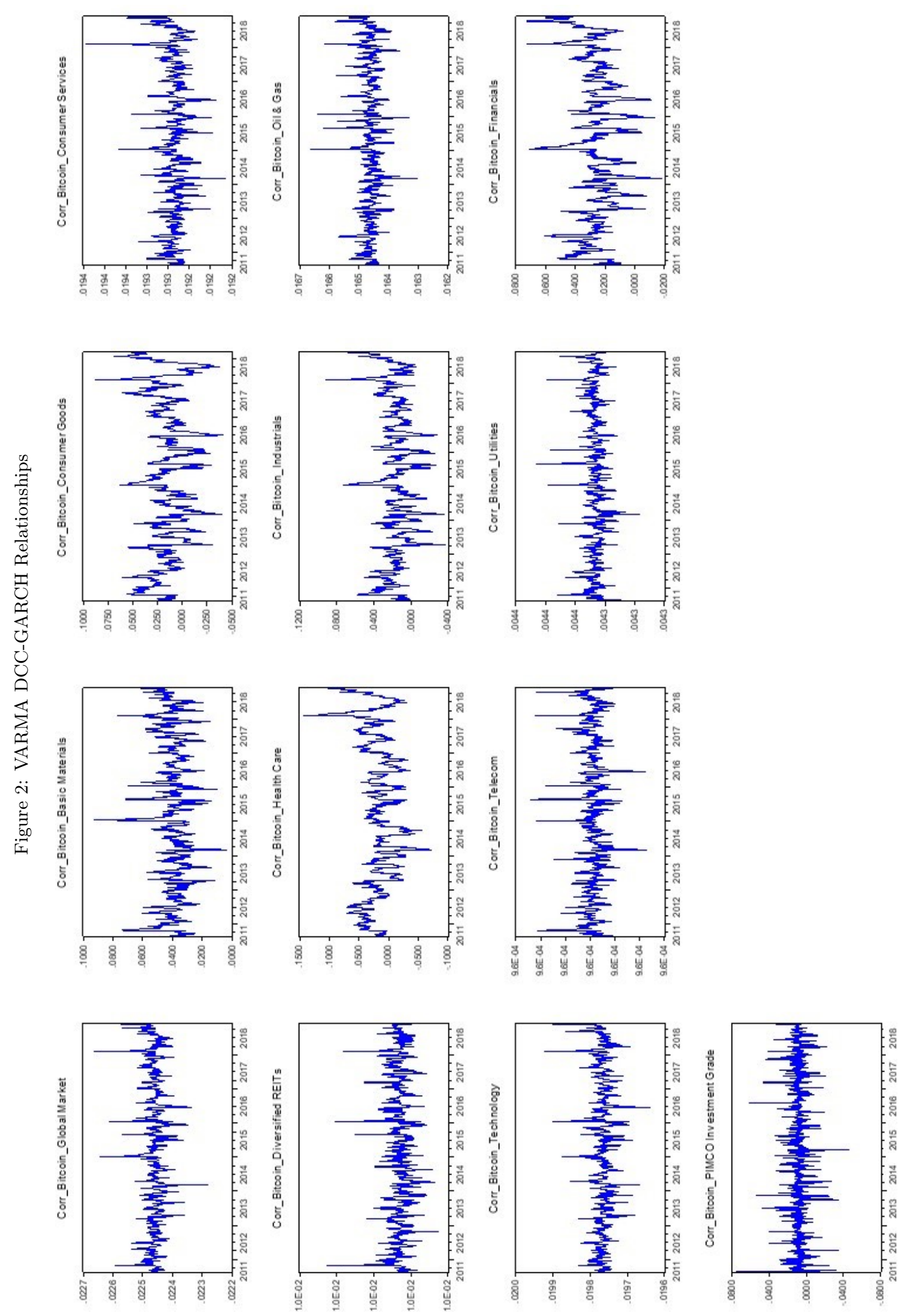

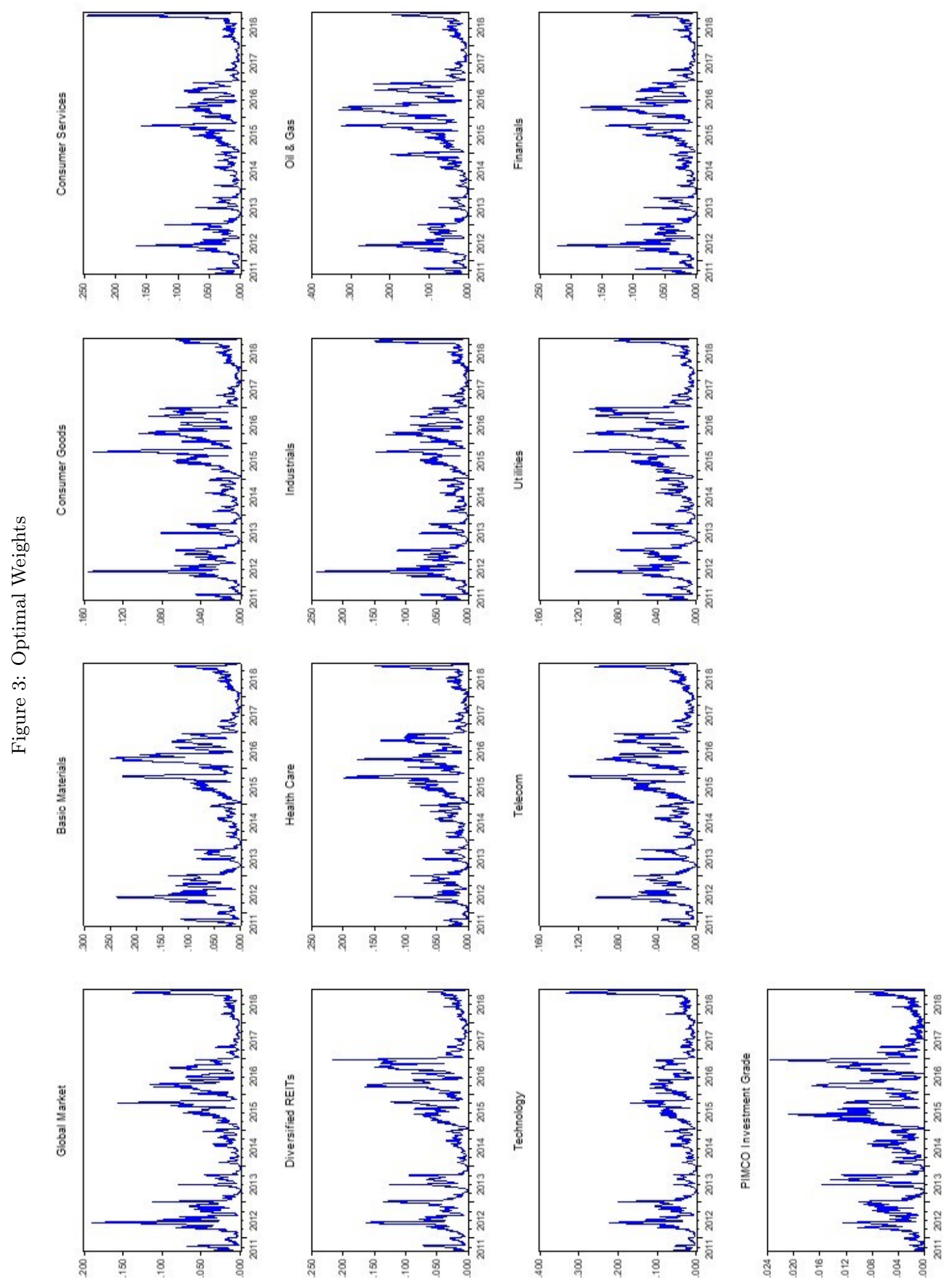

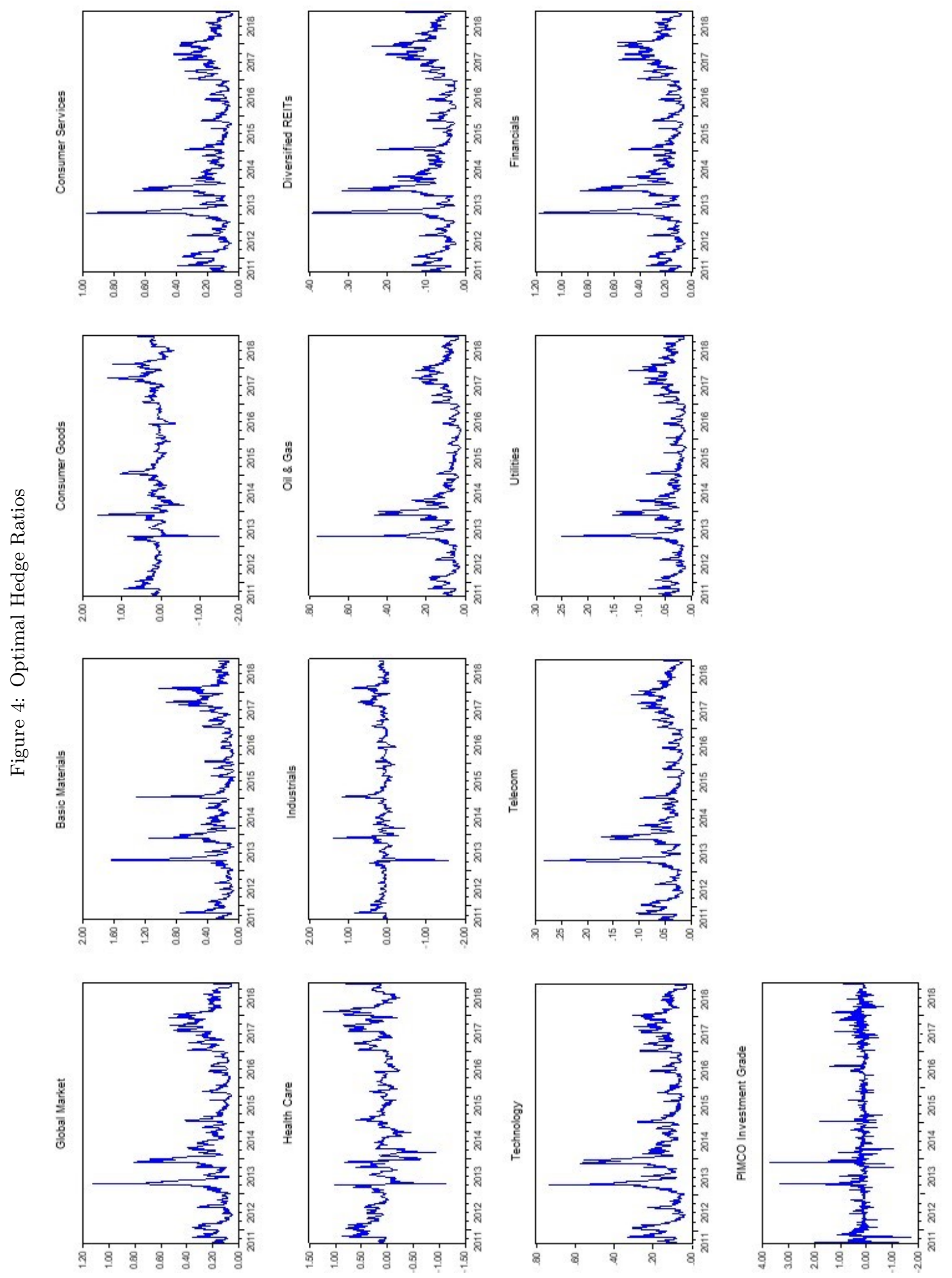


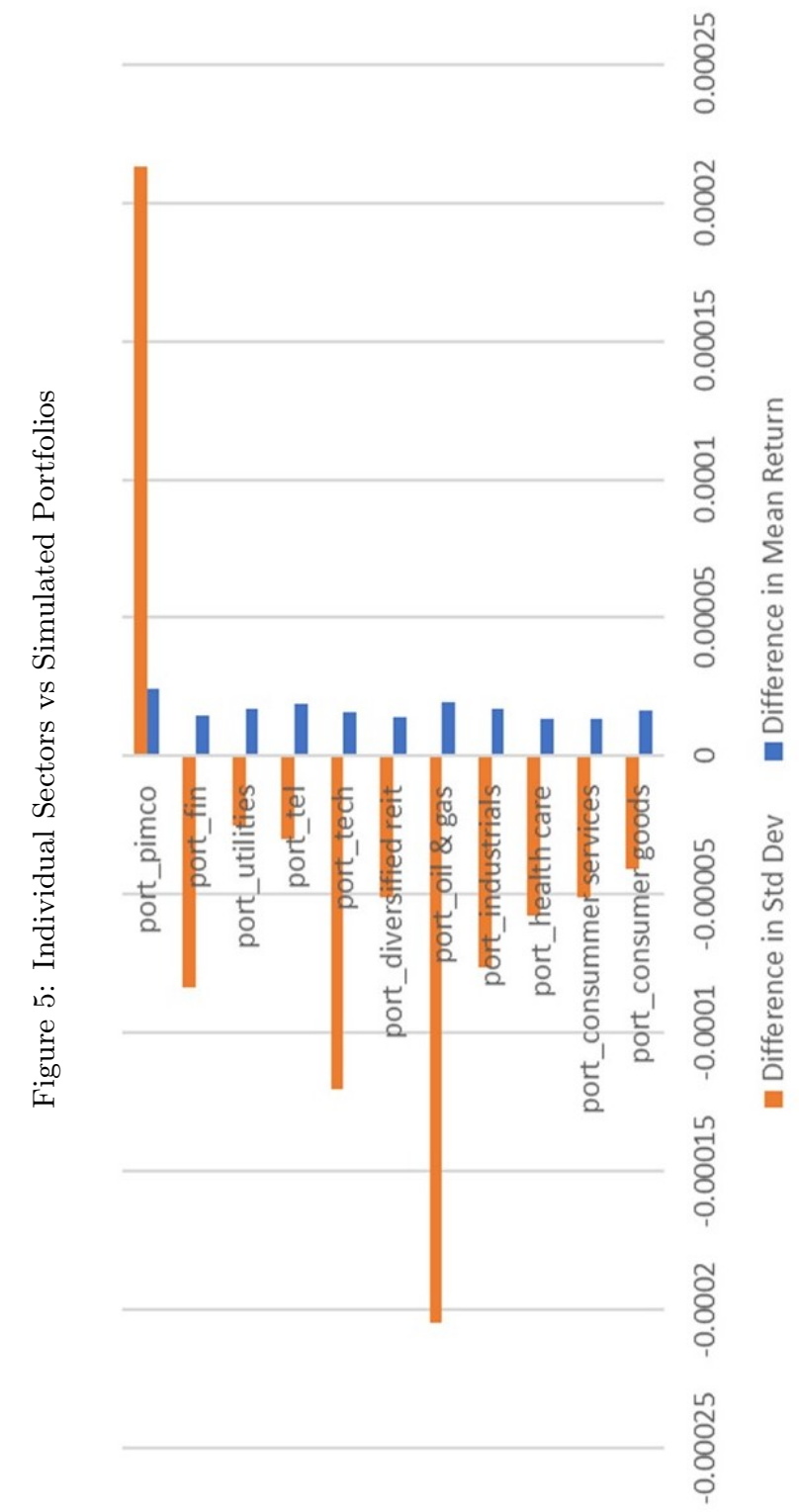


Table 1: Descriptive statistics

\begin{tabular}{|c|c|c|c|c|c|c|c|}
\hline & Bitcoin & Global Mkts. & Basic Mat. & Cons. Goods & Cons. Serv. & Div. REITs & Health Care \\
\hline Mean & 0.0031 & 0.0003 & 0.0000 & 0.0003 & 0.0004 & 0.0003 & 0.0005 \\
\hline Std. Dev. & 0.0601 & 0.0073 & 0.0100 & 0.0067 & 0.0070 & 0.0080 & 0.0073 \\
\hline Skewness & -0.9996 & -0.4944 & -0.2321 & -0.5459 & -0.5031 & -0.4683 & -0.4148 \\
\hline Kurtosis & 22.85 & 7.94 & 6.91 & 7.36 & 6.43 & 6.6 & 5.41 \\
\hline Jarque-Bera & $7241^{* * *}$ & $534^{* * *}$ & $1226^{* * *}$ & $1602^{* * *}$ & $1012^{* * *}$ & $1094^{* * *}$ & $515^{* * *}$ \\
\hline Q (10) & $27^{* * *}$ & $99^{* * *}$ & $121^{* * *}$ & $89 * * *$ & $74^{* * *}$ & $49 * * *$ & $55^{* * *}$ \\
\hline $\mathrm{ADF}$ & $-45^{* * *}$ & $-36^{* * *}$ & $-34^{* * *}$ & $-36 * * *$ & $-37 * * *$ & $-39 * * *$ & $-38 * * *$ \\
\hline (Pearson) Correlation with Bitcoin & 1.0000 & 0.0324 & 0.0629 & 0.0189 & 0.0246 & 0.0411 & 0.0206 \\
\hline & Industrials & Oil \& Gas & Technology & Telecoms & Utilities & Financials & PIMCO Bond Index \\
\hline Mean & 0.0004 & 0.0001 & 0.0006 & 0.0002 & 0.0002 & 0.0003 & 0.0001 \\
\hline Std. Dev. & 0.0077 & 0.0107 & 0.0088 & 0.0065 & 0.0068 & 0.0083 & 0.0027 \\
\hline Skewness & -0.3905 & -0.2 & -0.3492 & -0.391 & -0.4438 & -0.5183 & -0.2524 \\
\hline Kurtosis & 7.45 & 6.04 & 5.46 & 6.59 & 6.89 & 9.23 & 4.6499 \\
\hline Jarque-Bera & $1616^{* * *}$ & $745^{* * *}$ & $517^{* * *}$ & $1069 * * *$ & $1258^{* * *}$ & $3162^{* * *}$ & $235.81^{* * *}$ \\
\hline Q (10) & $118^{* * *}$ & $68^{* * * *}$ & $62 * * *$ & $62 * * *$ & $50 * * *$ & $96^{* * *}$ & $24^{* *}$ \\
\hline $\mathrm{ADF}$ & $-35^{* * *}$ & $-37 * * *$ & $-38 * * *$ & $-37 * * *$ & $-39 * * *$ & $-36^{* * *}$ & $-46^{* * *}$ \\
\hline (Pearson) Correlation with Bitcoin & 0.0264 & 0.0322 & 0.0343 & 0.0094 & 0.0088 & 0.0283 & 0.0147 \\
\hline
\end{tabular}

Note: $*{ }^{* *}$, and ${ }^{* * *}$ represent significant at the $0.10,0.05$, and 0.01 levels, respectively. 
Table 2: VARMA $(1,1)$ GARCH Parameters and diagnostics

\begin{tabular}{l|llllllll}
\hline \multirow{2}{*}{ Sector } & \multicolumn{3}{|c}{ Conditional Mean Equation } & \multicolumn{2}{c}{ Conditional Variance Equation } & \multirow{2}{*}{ Q(10) } & \multirow{2}{*}{$\mathrm{Q}^{\wedge} 2(10)$} \\
& Constant $(\mathrm{M})$ & AR $(1)$ & MA $(1)$ & Constant $(\mathrm{V})$ & ARCH & GARCH & \\
\hline Bitcoin & 0.0017 & $0.9879^{* * *}$ & $-0.9863^{* * *}$ & $0.57 \times 10^{\wedge} 4^{*}$ & $0.0154^{* * *}$ & $0.8505^{* * *}$ & $77.27^{* * *}$ & 4.27 \\
Global Market & $0.0005^{* * *}$ & 0.1411 & 0.0359 & $1.06 \times 10^{\wedge} 6^{* *}$ & $0.1061^{* * *}$ & $0.8730^{* * *}$ & 4.95 & 4.8 \\
Basic Materials & 0.0002 & 0.1629 & 0.0631 & $0.59 \times 10^{\wedge} 6^{*}$ & $0.0442^{* * *}$ & $0.9491^{* * *}$ & 10.19 & 6.64 \\
Consumer Goods & $0.0005^{* * *}$ & $0.1835^{* *}$ & -0.017 & $0.74 \times 10^{\wedge} 6^{*}$ & $0.0720^{* * *}$ & $0.9115^{* * *}$ & 4.34 & 4.47 \\
Consumer Services & $0.0006^{* * *}$ & 0.0423 & 0.0965 & $1.43 \times 10^{\wedge} 6^{* * *}$ & $0.1087^{* * *}$ & $0.8637^{* * *}$ & 3.30 & 8.29 \\
Diversified REITs & $0.0033^{* *}$ & 0.0787 & 0.0143 & $0.48 \times 10^{\wedge} 6^{*}$ & $0.0566^{* * *}$ & $0.9362^{* * *}$ & 9.62 & 9.27 \\
Health Care & $0.0007^{* * *}$ & 0.0487 & 0.0483 & $1.78 \times 10^{\wedge} 6^{*}$ & $0.0975^{* * *}$ & $0.8693^{* * *}$ & 9.53 & 9.18 \\
Industrials & $0.0006^{* * *}$ & $0.2166^{* *}$ & -0.126 & $1.52 \times 10^{\wedge} 6^{* *}$ & $0.1066^{* * *}$ & $0.8671^{* * *}$ & 4.77 & 5.22 \\
Oil and Gas & 0.0003 & 0.1803 & -0.0344 & $0.01 \times 10^{\wedge} 4^{* *}$ & $0.0754^{* * *}$ & $0.9174^{* * *}$ & 3.73 & 1.94 \\
Technology & $0.0009^{* * *}$ & 0.1035 & 0.0334 & $2.83 \times 10^{\wedge} 6^{* * *}$ & $0.0939^{* * *}$ & $0.8685^{* * *}$ & 13.76 & 3.72 \\
Telecom & 0.0002 & 0.0870 & 0.0594 & $1.03 \times 10^{\wedge} 6^{*}$ & $0.0633^{* * *}$ & $0.9115^{* * *}$ & 6.91 & 7.70 \\
Utilities & $0.0003^{* *}$ & 0.0191 & 0.0959 & $0.64 \times 10^{\wedge} 6$ & $0.0620^{* *}$ & $09236^{* * *}$ & 7.70 & 7.37 \\
Financials & $0.0053^{* * *}$ & 0.167 & 0.0137 & $1.15 \times 10^{\wedge} 6^{* *}$ & $0.0948^{* * *}$ & $0.8883^{* * *}$ & 5.30 & 2.94 \\
PIMCO Bond Index & $0.0001^{* *}$ & -0.0071 & -0.0464 & $0.0775^{* *}$ & $0.0343^{* * *}$ & $0.9547^{* * *}$ & 12.60 & 5.65 \\
\hline
\end{tabular}

Note: $*, * *$, and ${ }^{* * *}$ represent significant at the $0.10,0.05$, and 0.01 levels, respectively. 
Table 3: VARMA DCC-GARCH Analysis and Associated Diagnostic Tests

\begin{tabular}{|c|c|c|c|c|c|c|c|c|c|c|c|c|c|}
\hline & Global Mkt & Basic Mat. & C. Goods & Serv. & REITs & Health & Industr. & Oil \& Gas & Tech & Tel. & Util. & Fin. & Bond Index \\
\hline \multicolumn{14}{|l|}{ Average DCC } \\
\hline Full Sample & 0.0225 & 0.0395 & 0.0154 & 0.0193 & 0.0104 & 0.0175 & 0.0162 & 0.0165 & 0.0198 & 0.0010 & 0.0043 & 0.0261 & 0.0084 \\
\hline Difference in DCC & $-9 \mathrm{E}-06$ & $-4 \mathrm{E}-03$ & $-5 \mathrm{E}-03$ & $-5 \mathrm{E}-06$ & $-3 \mathrm{E}-11$ & $-1 \mathrm{E}-02$ & $-6 \mathrm{E}-03$ & $-9 . \mathrm{E}-06$ & $-6 \mathrm{E}-06$ & $-3 \mathrm{E}-10$ & $-1 \mathrm{E}-06$ & $-7 \mathrm{E}-03$ & $3 \mathrm{E}-04$ \\
\hline t-stat difference & $-5.44^{* * *}$ & $-7.53^{* * *}$ & $-5.06^{* * *}$ & $-4.62^{* * *}$ & $-1.98^{* *}$ & $-6.86^{* * *}$ & $-7.05^{* * *}$ & $-5.65^{* * *}$ & $-4.78 * * *$ & $-3.05^{* * *}$ & $-3.48^{* * *}$ & $-9.95^{* * *}$ & 0.81 \\
\hline \multicolumn{14}{|l|}{ Diagnostic Tests } \\
\hline LM Test of Tse (2000) & $752^{* * *}$ & $406^{* * *}$ & $169^{* * *}$ & $689^{* * *}$ & $815^{* * *}$ & $154^{* * *}$ & $246^{* * *}$ & $888^{* * *}$ & $803^{* * *}$ & $722^{* * *}$ & $805^{* * *}$ & $184^{* * *}$ & $4793^{* * *}$ \\
\hline Hosking Statistics(10) & 30.46 & 30.47 & 31.74 & 38.48 & 36.18 & 31.73 & 29.88 & 20 & 30.28 & 43.92 & 35.66 & 37.86 & 23.65 \\
\hline Li and McLeod's (10) & 30.46 & 30.49 & 31.74 & 38.47 & 36.19 & 31.73 & 29.88 & 20.05 & 30.28 & 43.89 & 35.67 & 37.84 & 23.68 \\
\hline
\end{tabular}

Notes: The Lagrange multiplier test of Tse [2000], Hosking [1980] and Li and McLeod [1981] checks the null hypothesis of constant correlation, no serial correlation, and no misspecification in the model, respectively. ${ }^{*}, *$, and ${ }^{* * *}$ represent significance at $0.10,0.05$, and 0.01 levels, respectively.

Table 4: Optimal weights and hedge ratios for portfolios

\begin{tabular}{|c|c|c|c|c|c|c|c|c|c|c|c|c|c|}
\hline & Global Mkt & Basic Mat. & C. Goods & Serv. & REITs & Health & Industr. & Oil \& Gas & Tech & Tel. & Util. & Fin. & Bond Index \\
\hline $\mathrm{Op}$ & 0.0255 & 0.0446 & 0.0235 & 0.0254 & 0.0346 & 0.0291 & 0.0290 & 0.0602 & 0.0402 & 0.0242 & 0.0256 & 0.0307 & 0.0043 \\
\hline Optimal Hedge Ratio & 0.2026 & 0.2552 & 0.1500 & 0.1717 & 0.0796 & 0.1472 & 0.1358 & 0.1027 & 0.1366 & 0.0462 & 0.0391 & 0.2207 & 0.1775 \\
\hline
\end{tabular}

